\title{
Violencia y resistencia en Final del Porvenir y All final de la calle
}

Roberto Rodriguez-Saona

r.rodriguez-saona@leedstrinity.ac.uk Leeds Trinity University

Resumen: El presente artículo aborda el tema de la violencia desde el punto de vista del personaje subordinado marginal y sus estrategias de resistencia simbólica y discursiva en Final del Porvenir de Augusto Higa y Al final de la calle de Óscar Malca.

Palabras clave: Literatura y violencia, narrativa peruana contemporánea, estrategias de resistencia simbólica y discursiva

Abstract: This article addresses the issue of violence from the point of view of the marginal and subordinate character and his strategies of symbolic and discursive resistance in el Final del Porvenir de Augusto Higa and Al final de la calle de Óscar Malca.

Keywords: Literature and violence, contemporary Peruvian narrative, strategies of symbolic and discursive resistance

T a violencia que caracteriza la vida cotidiana, especialmente aquella que tiene un carácter Lpermanente o estructural, y que se deriva de estructuras sociales, económicas y políticas injustas (Márquez 1994: 20) ${ }^{1}$, es la que condiciona la vida y motiva la resistencia de los personajes de las novelas que se comentan en el presente trabajo. Los personajes de las obras analizadas son seres marginales que adoptan estrategias subalternas para resistir la violencia vertical que los agobia. Esta resistencia no solo se halla en sus acciones sino también en sus actos simbólicos y discursivos (Leblanc 1999: 18).

1 Esta explicación de la violencia es expresada por Felipe Mac Gregor, S.J., en su prólogo a MAC Gregor, Felipe, S.J.; José Luis Rouillón, S.J. y Marcial Rubio Correa (eds.). Siete ensayos sobre la violencia en el Perú. Lima: Asociación Peruana de Estudios e Investigaciones para la Paz, 1985. 
ROBERTO RODRIGUEZ-SAONA

\section{Final del Porvenir, o la ciudad de lo criollo popular}

...todo habia concluido y ya no existian

ni inquilinos ni invasores

thal del Porvenir, publicada en 1992 por Augusto Higa, es una novela en la que se evoca
la vida cotidiana de los pobladores del conjunto habitacional El Porvenir, en el distrito de La Victoria, barrio de hogares humildes al sur este del centro de la ciudad de Lima. El barrio de La Victoria tradicionalmente ha sido asociado con las clases populares, en particular con la población afroperuana, mestizos pobres e inmigrantes llegados del interior del país, que en su mayoría terminaron dedicados al comercio en el mercado minorista del lugar, afincados en callejones, modestas casas alquiladas o que establecieron sus viviendas precarias en terrenos baldíos del distrito o en las faldas de los cerros aledaños (Panfichi 2000: 139). En el presente estudio estos distintos estamentos sociales quedan reunidos en la denominación de lo criollo popular (2000: 153). Desde este paisaje urbano marginal, los personajes libran una batalla para resistir la subalternidad reconvirtiendo su espacio privado, utilizando creativamente recursos de la cultura popular, y luchando por impedir el desalojo de sus viviendas en el edificio El Porvenir. Irónicamente, acentuando la exclusión que les impone la ciudad oficial, el barrio está situado justo fuera de donde antiguamente terminaba la antigua muralla del cercado de Lima, construida en tiempos coloniales para defenderla de ataques agresores y mantener aislada a la plebe (Higgins 2004: 45). En la novela, es la muralla invisible de la exclusión social la que aísla a los personajes de la ciudad hegemónica. Por otro lado, la peligrosidad del entorno que se describe en la novela, acrecienta el drama de marginación y resistencia de los personajes de Final del Porvenir.

Higa escribe su novela desde la perspectiva de la clase popular de La Victoria, y en ella somos testigos de las vicisitudes de los pobladores de un edificio multifamiliar, que luchan por sobrevivir en la precariedad de sus viviendas alquiladas, de las que los propietarios -El Banco Popular - tratan de desalojarlos. La novela se divide en dos partes. En la primera se hace hincapié en la vida cotidiana de los personajes; mientras que en la segunda parte, la sombra del desahucio se cierne sobre los pobladores del edificio y funciona como el principal hilo conductor de la historia. Al final son desalojados, con la complicidad de la policía, por otros invasores, que a su vez serán posteriormente desalojados por el ejército. Es 
la historia de los marginados que luchan infructuosamente frente al orden establecido y sus agentes. En El Porvenir no solo han construido su identidad sino que en él reconocen su diferencia con la ciudad oficial: están excluidos y la ciudad hegemónica les es inaccesible.

\section{Lenguaje y estilo}

El lenguaje y el estilo dan unidad a la novela. El lenguaje musical, poético, lleno de metáforas, cargado de una gran intensidad, agobiante -como la vida de los personajes- nos transmite el desaliento, el pesimismo y desencanto de los pobladores del edificio El Porvenir, pero al mismo tiempo deja entrever la alegría, la festividad y algarabía característica de las clases populares. El estilo de monólogo del narrador, casi de principio a fin, proporciona un tono agotador al relato, como la cotidianidad de los personajes que encontramos. El narrador es un observador de lo que ocurre. Se ve incluido ocasionalmente en la historia, pero no se encarna en ningún personaje específico. Es como la conciencia, que todo lo observa (Jara Jiménez 1998: 114).

\section{Un barrio criollo popular}

Final del Porvenir es un relato que transmite el punto de vista de lo criollo popular, entendido como un grupo o estamento social en el que lo que importa «es un código cultural de interacción social que incorpora selectivamente como iguales a todos aquellos que conocen sus prácticas de identificación ritual, sin hacer distingos étnicos o de clase» (Panfichi 2004: 39). Este carácter multiétnico se aprecia a lo largo de la historia, y así tenemos que desfilan personajes como el tío Américo, quien «con el andar cuadrado de los serranos» (1992: 8) batalla día a día como carretillero en el mercado y es un héroe para los niños del edificio; Johny, para quien el color de su piel es parte de su identidad a la par que su nombre o sus progenitores: «Me llamo Johny, el zambo Johny, soy hijo de mamá Casania y de papá Onésimo» (1992: 11); Doña Francisquita, tendera de un puesto en el mercado, «mujer alta, blancona, de rostro abotagado» (1992: 49); Dońa Fernanda de Acevedo, recién llegada al barrio, «de una piel blanca aceitada» $y$ «con un ligero acento extranjero en el saludo» (1992: 21); o el asiático don Pin Pin, «Un chino enjuto, deleznable, pintoresco en el andar y de rostro mortecino» (1992: 122). La descripción de la comunidad de personajes no importa por sus detalles sino por el carácter heterogéneo de su composición, de su interacción, por la «solidaridad entre iguales» (Panfichi 2004: 39) que expresará resistencia al contrastar con la exclusividad que caracteriza a la clase dominante, a la ciudad oficial. 
En Final del Porvenir hallamos impregnada la visión del mundo del barrio pobre, en efervescencia constante, con sus habitantes despojados de privacidad en el corralón, callejón, casucha, edificio comunitario. La fatalidad, la desilusión, el fracaso son constantes en la novela, pero también como contraste la vitalidad, la alegría y la extroversión de las clases populares. Están condenados a perder, pero aun así libran una batalla constante por sobrevivir. Lo criollo popular, no solo está determinado por índices socioeconómicos, es «un estilo de vida donde juega un papel importante el sentido de la gracia, la picardía y el espectáculo exhibicionista» (Panfichi 2004: 38). El padre del narrador es un ejemplo de este comportamiento social:

Y luego caminaba exhibicionista, ancho de espaldas, las piernas cimbreantes, el saco a cuadros y de rodate amplio, la corbata mariposa, su metro ochenta, sus 102 kilos, y los esquivos zapatos de charol, balanceándose al ritmo de su cuerpo empedernido. [...] No le tenía miedo a los delincuentes ni a los pandilleros, ni a los vigilantes, por el contrario, los curiosos se trompeaban para verlo bailar, haciendo piruetas, malabares, acrobacia, en el centro de un ruedo, contaba chistes truculentos, ensayaba su voz de barítono, y agitado, tembloroso, prometía la leche y la carne a los humildes, la voluntad del pueblo era no morirse de hambre. (1992: 19)

Las minuciosas y detalladas descripciones de los personajes y de sus manías, actitudes y virtuosidades sirven precisamente para llevar a un primer plano a este segmento periférico de la población limeña y al mismo tiempo plantea una tensión con la ciudad oficial, impenetrable, invisible, ausente en el lenguaje descriptivo de la novela.

\section{Una novela de aprendizaje}

Solamente vivimos para trabajar, comer y fornicar. No hay más verbo entre nosotros

\footnotetext{
Conforme avanza el relato, los niños del comienzo de la historia se van transformando paulatinamente en adolescentes y jóvenes adultos. La novela es también una novela de aprendizaje. Uno de los personajes representativos del proceso de maduración gradual es el joven Matías, estudiante de filosofía, el único que accede a la educación superior, quien observa la llegada de numerosos migrantes de provincias que bajan de los ómnibus interprovinciales y se pregunta con melancolía: «¿Qué harán? ¿A dónde irán?» (1992: 116). Más que preguntas retóricas, son
} 
cuestionamientos, interrogatorios, interpelaciones a la ciudad hegemónica, a la sociedad en su conjunto, que no está preparada para atender el crecimiento demográfico de la capital.

Aunque a su arribo el joven Matías es mirado con cierto recelo por los pobladores del edificio, este es aceptado después de mostrar sus cualidades de adivino y con ello obtener un empleo en la panadería del barrio.

Desde ese día quedamos ligados a su existencia, a pesar suyo y a pesar nuestro, no obstante que los estudios en la universidad lo alejaban de las conversaciones de los pasillos, de los balcones, y la gruta de la Virgen. Pero don Nico, papá, mi hermano el Pelelén, y todo el vecindario sabía que caminaba, respiraba, sonreía, trabajaba en la panadería, le decían el trujillano Rodríguez, un muchachón confidencial, pacífico, inventor de historias, consejero de las adolescentes, tocaba la guitarra, poseía buena voz, y era el único amigo del tío Américo. (1992: 71)

Matías se encarga de tratar con propietarios, abogados y autoridades en defensa de los inquilinos, y comprueba que los mecanismos formales de la justicia y la legalidad están orientados desfavorablemente hacia los de su clase social. Matías, el inventor de historias, el de la buena voz, representa a la futura generación de los subalternos, que gracias al acceso a la educación alcanzará movilidad social y llegará a escribir sus historias, a ficcionalizar sus vidas, a insertarlos en la ciudad letrada.

Otros personajes van evolucionando en su personalidad conforme avanza la historia, como en el caso de la niña Gala transformada en adolescente, "Con el tiempo, Gala se fue transformando, ya no era la palomilla que saltaba charcos, tampoco nos acompañaba en las correrías por los bajos fondos» (1992: 74). La discriminación social va de la mano con el color de la piel, pero a pesar de ello el desarrollo de la vida emocional y sentimental de los personajes jóvenes sigue su curso: «No obstante su color de cuervo, nos enteramos que la rondaba un individuo, ella consentía largas charlas en el patio, y como su madre Olinda Campana se opusiera, salió a relucir su carácter inflexible» (1992: 74) Más adelante, esa inflexibilidad de carácter le serviría de mucho para encabezar la resistencia a los matones invasores contratados por el Banco Popular para obligarlos a abandonar el edificio. Ante las dudas de Matías sobre cómo defenderse de la invasión de los matones alquilados por los propietarios para desalojarlos, Gala plantea sus ideas sin ambigüedades: 
- Matías dejó de caminar, se arregostó a la pared. Debían ser como las ocho de la noche. Gala insistió:

- Cualquier cosa, gritar, reclamar, negarse a salir, resistir con palos. Por lo menos detenerlos, si nos defendemos no nos tocarán. .

- No estés tan segura.

- ¿Hay otra forma?

- ¡Qué sé yo!

- Solo cabe atrincherarse.

- Ya habrá otra salida.

- No hay otra salida. (1992: 172-173)

Incluso cuando los invasores casi habían triunfado en su encargo de establecerse en las azoteas del edificio, y Matías había sido golpeado y derrumbado al suelo perdiendo el conocimiento, Gala continúa luchando, tratando de cobrar venganza sobre los llamados descamisados: «Si Matías perdió el conocimiento, en cambio Gala, los vecinos de Giribaldi y los de América, acometieron violentos, una vez en la azotea, destrozaron las casuchas, volcaban pilotes, echaban mesas y rompían colchones» (1992: 184).

Esto no solo es significativo por tener Gala un papel activo en la acción contra los invasores, sino que, si Matías representa al futuro escritor, este solo podrá completar la historia con la colaboración de Gala, puesto que él, inconsciente al final de la epopeya vecinal, precisará de la versión de Gala para completar los fragmentos de la memoria escrita. Las mujeres están presentes como fuerza social y literaria.

\section{Personajes y estrategias de resistencia}

Los personajes se caracterizan por su instinto de auto-conservación. Son pobladores de un barrio pobre que luchan por sí mismos. No tienen fe en las autoridades ni en las instituciones oficiales. Desfilan por las páginas de la novela obreros, vendedores, peluqueros, remalladoras, predicadores, cantineros, pero también prostitutas, ladronzuelos, estafadores, y otros delincuentes variopintos. Aislados en un rincón de la ciudad, la marginación -pero al mismo tiempo la resistencia- está representada por una multiplicidad de rostros, nombres, oficios, delitos menores, hitos, espacios públicos ajenos y restringidos espacios privados, que sirven para repetidamente señalar la inaccesibilidad de la ciudad oficial para los pobres, los marginales, los excluidos. 
Aunque el edificio El Porvenir era un lugar tradicional en su organización social, con los hombres parados en las esquinas, en la peluquería, en el billar, y las mujeres generalmente desempeñaban el esperado papel de esposa y madre, ellas también trabajaban y contribuían activamente a la manutención del hogar, desplegando infinidad de habilidades y destrezas, o incluso llevando un negocio, como lo demuestra doña Francisca:

Doña Francisquita se batía incansable, demoledora, rozagante en sus dos metros de espacio, abría sus brazos, movilizaba su enorme humanidad, sacaba los paquetes de arroz, amontonaba la manteca, despachaba las aceitunas, regalaba caramelos, atendía los pedidos de sal a granel, envolvía la avena, juntaba la canela, añadía lápices de labio, porongos de colonia, conversaba con los proveedores, sudaba si llegaban los niños, resoplaba, machacaba, insistía, pulverizaba, quebrantaba, tronchaba, colocaba el dinero en la caja, y todavía embuchaba una ración de pan con relleno, tomaba su vaso de emoliente, y gritaba a los indecisos, avergonzaba a los regatones, se prestaba detergentes y bolsitas de ajos de sus vecinos, y se preciaba de hacer las mejores ofertas de todo el Minorista. (1992: 52- 53)

¿En su lucha por sobrevivir, los personajes transforman sus casas en comercios escondidos en los que se dedican a oficios menores y trabajos manuales, estrategias de supervivencia cotidiana de los pobres, que la novela reivindica: «No era un secreto que Prudencio López atendía un taller de curtiembre, la enfermera Ana remallaba medias. Guadalupe Marengo, [...] fabricaba sellos de jebe y grababa tatuajes» (1992: 60). Estas características fundamentales de la identidad de la clase criolla popular no solo son rasgos que se asocian históricamente a la cultura afroperuana y a la picaresca espańola, sino que llegan a ser formas de resistencia y de lucha contra la pobreza (Panfichi 2004: 39).

\section{Narrador que enuncia la resistencia}

La novela es presentada casi en su totalidad como un prolongado monólogo interior del narrador-personaje. En el narrador tenemos a «la conciencia atormentada y apabullada por la monótona cotidianidad del hombre de este siglo y la urbe de Lima, la capital del Perú y sus habitantes de clase media o baja, turbados por una infinidad de problemas propios de una ciudad que crece desordenadamente en sus extramuros sin planificación alguna» (Jara Jiménez 1998: 109). 
El narrador recuerda lo que pasó cuando era niño y por ello se entiende y acepta lo que se narra de forma aumentada, exagerada por la memoria y la imaginación infantil. En ocasiones, el narrador interviene en la historia, pero no modifica los hechos:

Hasta que llego yo, lo encuentro echado, lo despierto, y me distingue confuso.

- No pude venir más temprano, le digo.

Entonces se incorpora, se restriega la cara, se limpia el pantalón, se coloca la chompa. "Soñé que jugaba a los dados y perseguía muchachas", me cuenta. Le toco el estómago vacío:

- Sueñas cojudeces. (1992: 41)

Si bien es cierto que el espacio en que se desenvuelven y sus lugares propios sirven a los personajes de la novela para desplegar una tenaz resistencia a la discriminación y exclusión social, el discurso del narrador es también un mecanismo de resistencia: inventar recuerdos también es una forma de resistir. El edificio es el espacio físico desde el que los vecinos resisten el desahucio, la exclusión. El monólogo del narrador es el espacio enunciativo desde el que también se articula dicha resistencia.

\section{Marginación: de la Parada a la paradoja}

¿Dónde queda Comas? Al norte de la ciudad. Un enorme pampón. No hay caminos, no hay agua, no hay luz.

\footnotetext{
T a marginación de los personajes es intensa en la novela porque el ambiente topográfico Uen el que se desenvuelven es limitado. Por lo general, la acción se desarrolla solo en el edificio, en el mercado de La Parada y en unas pocas calles de La Victoria. Cuando salen de esas calles solo es momentáneamente, temporalmente para cumplir alguna tarea específica, pero luego vuelven a su territorio. Los pobladores están marginados geográficamente pero además están marginados socialmente: sus vidas se caracterizan por la supervivencia del día a día. El sistema no les proporciona instrumentos de integración social. El barrio secciona
} 
a sus habitantes, los define, juega un papel primordial en la formación de su identidad, en base a criterios raciales, étnicos y de condición social.

Incluso alguna persona que tuviera buenos motivos para traspasar las fronteras del distrito, como don Eloy, que tiene un empleo en una fábrica textil, vuelve cada día a su hogar, «a una casa que era la misma de la mañana, igual a la de ayer, idéntica a la de hace un año, y la misma de siempre: una caja de zapatos dividida en compartimientos» (1992: 81). El contacto de don Eloy con la ciudad oficial, como obrero textil, no produce ningún cambio en su vida, la de su familia o de la comunidad. Ellos solo se sienten seguros de su paisaje inmediato, ellos son solo dueños de su miseria. En otro momento de la novela cuando un grupo de pobladores del Porvenir sale de una infructuosa visita a la sede principal del banco que quiere desalojarlos, situada en el centro histórico de la ciudad, los personajes «no se dieron cuenta de los letreros, las tiendas comerciales, los restaurantes y vidriados, los avisos luminosos, y el tranvía chirriante», las expresiones de modernidad en el seno de la ciudad dominante son prácticamente invisibles para ellos, es un mundo ajeno. Es solo cuando llegan a una calle que les es conocida por estar en la ruta de transporte público hacia su barrio, que empiezan a recuperar la conciencia de su ubicación:

El tremendo gentío de Abancay les sorprendió. Sobre el bramido de los carros fueron incorporándose a la realidad, estaban apostados en una pista, en el momento que tomaron el ómnibus, la apretadera les dio nociones de sus cuerpos, llegaron al bar de Parinacochas conscientes de sus personas, al primer trago recordaron sus nombres, las edades, los pesos. (1992: 169)

Solo al llegar de regreso a su entorno cotidiano, -al barrio El Porvenir- recuperan totalmente la conciencia y vuelven a tener noción cabal de su identidad personal y colectiva. Desde las primeras líneas de la narración ya había quedado clara la importancia e influencia del entorno, del paisaje urbano que rodea a los protagonistas, en la conformación de su identidad, en su percepción del mundo:

La Victoria era un enorme distrito color del hormigón, en los extramuros de la ciudad, en los límites con los algodonales, muy cerca a los disminuidos establos, en las proximidades de los canchones de alfalfa, y todavía se respiraba el aire de los eucaliptos, y se comían pacaes en los huertos, y se podían ver los gallinazos en el cielo, rondando los basurales, por encima de los techos de adobón. Los nińos no se apartaban de sus casas, ni de los corralones, ni de las barriadas, y el paisaje diario 
lo establecían irregulares, diminutos monumentos en las plazoletas, y luego los edificios desparramados aquí y allá, embrollados con las residencias de ladrillos, confundidos con las boticas, mezclados con los domicilios de concreto. (1992: 7)

La íntima identificación de los vecinos con su barrio a pesar a la marginalidad de su entorno, su resistencia frente al desalojo ordenado por los dueños del edificio, auxiliados por la insensibilidad de las instituciones, de las autoridades y de las entidades financieras, habrán de servir de aliciente para desarrollar una actitud de resistencia ante la adversidad, la subalternidad y la marginación, que se percibe por toda la novela. El Banco Popular, propietarios del edificio El Porvenir, les ha planteado a los inquilinos que compren las viviendas o desalojen el edificio. Como los inquilinos no tienen dinero para comprar los departamentos y se niegan a salir, el banco les ha entablado juicio para obligarlos a dejar el lugar. No hay otra alternativa. La constante amenaza del desahucio, al que no saben cómo enfrentarse, es una muestra de la marginalidad de sus vidas. No hay leyes ni autoridades que los defiendan. Si alguna vez las leyes les dan la razón, estas son manipuladas por los poderosos en perjuicio de los inquilinos. Los personajes viven en los márgenes de la ciudad, se desenvuelven también en los márgenes de la ley.

Cuando finalmente los invasores contratados por el banco toman a la fuerza la azotea del edificio, los pobladores se quejan a la Prefectura y como resultado la policía se presenta, pero no interviene. Cuando los pobladores ya son incapaces de oponer resistencia a la invasión, la policía no solo no actúa sino que facilita la acción de los matones contratados por el banco: «Nadie lo impedía. El carro policial se estacionaba en la Bolívar, absteniéndose de intervenir, vigilaban las cuatro calles» (1992: 185).

Las autoridades y los dueños además de no preocuparse por los pobladores de El Porvenir, permiten la destrucción del lugar y promueven una reubicación en un lugar que es aún más marginal. En el contexto histórico de la novela, Comas es un lugar lejano, desconocido y desértico, como lo demuestra el diálogo entre Gala y Matías:

- Seguimos igual, exclamó Gala.

- Quieren reubicarnos en Comas.

- ¿Dónde queda Comas?

- Al norte de la ciudad. Un enorme pampón, no hay caminos, no hay agua, no hay luz. (1992: 172) 
Como profética paradoja, los vecinos serán reubicados en la pampa de Comas, en lo que entonces eran las lejanas afueras de la ciudad, pero que después hacia fines del siglo XX habría de formar parte de lo que sería uno de los ejes socio-económicos más importantes del crecimiento de la capital: el Cono Norte, una nueva zona de Lima, con una nueva dinámica multicultural y multiétnica hecha realidad por el esfuerzo sostenido de lugareños e inmigrantes pobres: los nuevos limeños (Matos Mar 2000: 137).

\section{Gente despreciable en una ciudad impenetrable}

...comiendo vidrios, arando en las rocas, durmiendo en la interperie, solamente para que se les reconociera como gente despreciable

$\mathrm{D}$ e principio a fin la novela nos envuelve en la marginalidad geográfica y social de sus personajes y de su entorno cotidiano. Viven en un edificio de hormigón, pero el material noble de la construcción esconde la precariedad de la vivienda alquilada. Los inquilinos están a merced de los propietarios, del aumento del alquiler que no podrán pagar y que los llevará a la derrota final por conservar sus hogares, y que además terminará en una mayor discriminación social al ser reubicados en una zona aún más marginal.

La novela describe la marginación y al mismo tiempo la lucha por sobrevivir en medio de los problemas cotidianos que la gente pobre vive en los barrios populares de una urbe que les resulta impenetrable, inaccesible. Lo cotidiano está marcado profundamente por las dificultades económicas y sociales. Las preocupaciones de los vecinos giran en torno a las necesidades básicas y la imposibilidad de satisfacerlas. Doña Olinda Campana, una de las vecinas de El Porvenir, mientras conversa con otra vecina del edificio «...escuchó decir que el arroz escaseaba, ya no se podía con el alquiler de la casa, la gente es cada vez más mala, no hay moral» (1992: 32).

Sus preocupaciones están íntimamente asociadas al esfuerzo por sobrevivir. La inflación, el alza del dólar, el precio de los artículos de primera necesidad, el dinero para pagar el alquiler. En las pequeñas viviendas del edificio, en su patio, en las azoteas y balcones, en las calles que frecuentan, al pie del poste de luz, junto a la gruta de la Virgen, en los mercados y mercadillos cercanos, en la peluquería y establecimientos comerciales, en los parques y plazas de la zona los vecinos de El Porvenir construyen su identidad cultural como 
criollos pobres y retan a la ciudad oficial para que se les tome en cuenta como peruanos con derecho a cruzar las fronteras de la pobreza y la subordinación social para formar parte activa de la vida nacional. Los vecinos de El Porvenir son derrotados en su lucha por conservar el lugar que les ha servido para construir su identidad, individual y colectiva, pero a pesar de haber sido vencidos, el cuestionamiento, la interrogación, el reto a la ciudad hegemónica queda, puesto que el problema fundamental de exclusión de las mayorías no se ha resuelto. La ciudad oficial sigue siendo un espacio de concentración de poder y dominación.

Aunque el poder económico de los propietarios y la falta de asideros legales y de apoyo institucional derrotan finalmente a los pobladores de El Porvenir, queda una luz de esperanza simbolizada por la presencia de Pelelén, el hermano menor del narrador, como la última persona que permanece sobre la azotea del edificio finalmente desalojado por el ejército, jugando como siempre lo hizo, como anuncio de que el final de su vida en el conjunto habitacional es en realidad el inicio de un nuevo porvenir.

\section{Al final de la calle, o la ciudad urbano juvenil}

Oscar Malca, el autor de esta novela, es un joven escritor que empezó su labor literaria en el circuito subterráneo o alternativo de la ciudad de Lima. Ha dirigido publicaciones relacionadas con la música rock y su novela ha sido llevada al cine con el título de Ciudad de $M$. La fragmentación que caracteriza a la novela refleja la fragmentación social tan típica de la época en que se sitúa la historia, a finales de los años 80 y comienzos de los 90 . $\mathrm{Al}$ final de la calle no tiene una estructura formal convencional, sino que está constituida por una sucesión de vińetas o secuencias, en las que la ciudad de Lima, y en particular el barrio de Magdalena, son la columna vertebral que sostiene la narración como espacio de identidad y de manejo de crisis personal y social de los personajes. La novela consta de 22 secuencias más un prólogo y un epílogo. Sólo tres secuencias están directamente interconectadas entre sí, y las tres comparten el mismo título: La ruta de Magdalena. El barrio, el distrito, ese paisaje urbano inmediato de los personajes, con el cual se sienten íntimamente identificados, es utilizado como elemento estructurador de la novela, como un modo de construir un imaginario alternativo antihegemónico que se opone y resiste la violencia de la exclusión social, particularmente de los jóvenes. Otras dos secuencias son las únicas que tienen linealidad y aparecen de forma consecutiva bajo los títulos Nadie sabe para quien trabaja 1 y 2. Los caminos que conducen por y hacia la ciudad hegemónica están 
fragmentados, como la novela, y solo conducen al fracaso. Al final de cuentas $\mathrm{M}$ tiene que optar por la ruta alternativa de la ilegalidad para buscar su ascenso social.

Aunque Al final de la calle ha sido condenada por una parte de la crítica por su falta de profundidad debido a la «impericia del autor» (Bances 2003: 1), o por la «racionalidad cínica de los personajes, que les impide cuestionar el medio en que viven» (Vega 2004: 4), ha tenido también considerable aceptación crítica por su discurso y temática (Sumalavia 2002: 5), por ser la única que «cristaliza las posibilidades» de la novela juvenil (Velásquez Castro 2004: 1), por su utilización de la cultura popular, en particular el fútbol, para construir una realidad urbana del mundo juvenil subterráneo (Wood 2005: 276), o por ser la novela «más radical y coherente» de las que tratan el tema de la marginalidad juvenil (López Degregori y Eslava 2001: 256).

En Al final de la calle, se comprueba una vez más que Lima a finales del siglo XX no es la mítica arcadia post virreynal que se había creado en cierto imaginario tradicional, sino un espacio propicio para la violencia y la marginación, no solo de aquellos que llegan a su periferia provenientes de las provincias, sino de los jóvenes que pertenecen a su clase media autóctona, grupo social que ha perdido su posición en la sociedad, lo que está representado por el decadente barrio de Magdalena, que también ha perdido su posición dentro de la ciudad. Este distrito se describe como «antiguo distrito limeño» que en algún tiempo pasado fue elegante, pero en el que ahora «la mayoría de las maderas están picadas, y descoloridas, los techos parchados con cemento o calamina y las otrora imponentes mansiones, completamente tugurizadas y herrumbrosas» $\mathrm{y}$, aunque «todavía hay algunas [mansiones] que mantienen frágiles resabios de elegancia, [...] igual dan pena» (2000: 63).

Magdalena es una metáfora de Lima (Higgins 2004: 363), que permite contemplar a la ciudad toda como un espacio en crisis, inercia y abandono en el que los jóvenes no encuentran su lugar. Esa ciudad física, enferma, con su decadencia y falta de oportunidades para los jóvenes es una contradicción, y a la vez un cuestionamiento, de la falsedad de la aparente modernidad proclamada por el gobierno de Alberto Fujimori, que había adoptado medidas neoliberales extremas como solución precisamente a estos problemas. La desubicación de los jóvenes, su aparente inercia, sus actitudes frente al deporte y a la música popular, su búsqueda incesante de empleo e ingresos que les permita emancipación e independencia, son gestos de resistencia y transgresión frente a una ciudad oficial que los margina.

La novela se abre en la avenida La Colmena en el centro de Lima, que se nos presenta como ciudad del comercio informal, caótica, delincuencial y marginal. Aunque se 
está en pleno centro, este aparece degradado y marginal, y en él encontramos prostitutas, ladrones, ancianos como los primeros personajes de la historia. La Colmena, inaugurada en 1898, fue un símbolo de la modernidad de Lima en la primera mitad del siglo XX, pero aparece ahora como un lugar deteriorado y venido a menos. El asombro que causó la suntuosidad afrancesada de los edificios a cada lado de la moderna avenida, ha dado paso a un sentimiento de lástima por una calle desordenada y amenazante, como el que experimenta $\mathrm{M}$, el personaje principal de la obra:

Caminaba sin rumbo por La Colmena, mirando los escaparates y los carteles chillones que emergían de los muros en medio del desorden y la bulla de la avenida. Caminaba entre claxons que estallaban uno tras otro, revistas usadas y navajas de afeitar que se esparcían en el suelo al lado de charcos malolientes y mutilados que pedían limosna casi amenazando a los transeúntes. (2000: 17)

La amenaza de la violencia cotidiana de la gran ciudad permea por toda la novela, e incluso se halla incluida en el prólogo, en el que el autor tipifica la cotidianeidad de la agresión en las calles limeñas: «Porque es eso lo que la ciudad, en tanto espacio en el que diariamente me muevo, ha representado siempre para mí. Un lugar en el que todo el tiempo había que estar preparado para enfrentar relaciones de fuerza» (2000: 9).

Esa violencia diaria que reviste a la ciudad se materializa desde el episodio de apertura de la novela en que $\mathrm{M}$ es testigo de un asalto y robo a una pareja de ancianos, que llevado por su instinto logra frustrar. La intervención de $M$, que hace caer al asaltante que escapa corriendo, motiva a otros transeúntes a actuar y capturarlo. Este hecho participatorio contrasta con el tono general de la novela que nos deja la sensación de inercia, de inoperatividad, pasividad -más aparente que real- de los jóvenes protagonistas: «¿Cuál era la diferencia entre la engañosa seguridad de la inacción, la inercia y una mujer que lo succionaba como un vigoroso remolino en medio del quieto océano?» (2000: 170). El joven protagonista manifiesta su hartazgo con su situación pero tiene un profundo temor de arriesgarse a cambiar. Sabe que cualquier situación posiblemente será mejor que la que tiene ahora pero «qué difícil alejarse de donde había vegetado durante años hasta traducir en comodidad lo que no era sino la adocenada, ruidosa vacuidad de una vida anestesiada por la mutua conmiseración entre él y sus amigos» (2000: 170). Aunque difícil, al final superará su autopercepción fatalista y negativa, y se irá, rompiendo con todo lo que significa esa vida rutinaria y vacía. 


\section{La ciudad, el barrio, espacio e identidad}

La novela no contiene un tono condenatorio de la ciudad de Lima, sino que se ve la ciudad como una realidad objetiva. Para el autor, Lima no es «ni señorial, ni horrible, ni mala, ni buena, Lima es tal como es y punto» (2000: 10-11). Sin tono glorificador nos presenta el submundo juvenil en el que un paisaje urbano de violencia, drogas y música son las señas de identificación de este universo. El episodio titulado Masca fierro ilustra con eficacia este submundo cuando $M$ sufre el asalto de dos drogadictos que lo atacan en venganza por una supuesta adulteración de la cocaína que M les había proporcionado. El ataque sucede mientras se escucha en el fondo la música de grupos musicales techno-pop como Depeche Mode, New Order y Midnight Oil, referentes constantes en la novela de Oscar Malca. La violencia, drogas y música son marcadores de identidad, y fuente de ingresos económicos, de los personajes en el paisaje urbano de Lima, en el que se les han cerrado las puertas del ascenso social convencional.

Dentro del macrocosmos que es Lima, hay un microcosmos que es el barrio de Magdalena, cuya importancia en la novela se ve acentuada por la presentación de tres viñetas sobre el distrito, que están escritas en letra negrita. Estas secuencias nos dejan la idea de que estamos ante un pueblo fantasma, una zona en abandono, de un lugar del que «hoy no quedan sino residuos» (2000: 64). Su estado se explica por el éxodo de muchos de sus habitantes en los años cuarenta a distritos más prestigiosos, y desde entonces «todo tiene que haber sido desgaste, irreversible y persistente deterioro» (2000: 63). Magdalena resume en buena medida lo ocurrido en Lima a partir de los años 40, en que un cierto proceso de industrialización, la migración masiva del campo a la ciudad, y otros factores sociales habían cambiado la distribución de la población en los distritos limeños. La burguesía se fue reubicando en otros distritos de la capital y pobladores de capas más populares los fueron reemplazando. La novela no sugiere, sin embargo, que Magdalena sea un lugar 'maldito'. $\mathrm{Al}$ contrario, dentro de su descomposición y deterioro «...es un buen barrio para vivir. Uno de los tantos huecos negros de la ciudad de Lima: sorprendentes, ignorados y sin embargo con una vigorosa identidad» (2000: 175). En ese 'buen barrio para vivir' aún pueden creer en la acción en conjunto, en común para alcanzar metas, aunque solo sea al formar equipos espontáneos de fútbol, jugando contra las normas, en el jardín del parque público o en la calle, o escuchando y tocando música rock, cuyo alto volumen permite ejercer una voz de protesta, diferente, bulliciosa, rebelde. 
$A$ I final de la calle es una novela en la que el vínculo de solidaridad que ofrece la pandilla sustituye al de la familia. Los personajes no logran conocerse ni reconocerse en su entorno inmediato, por ello se orientan al placer instantáneo antes que a la reflexión. No conocemos a los padres, hermanos, o familiares de los personajes. Solo la madre de $\mathrm{M}$ hace una aparición fugaz en la narración en su puesto de trabajo en un hospital público. La función del barrio como formador de identidad es fundamental para personajes y escritor, como lo confirma el autor otra vez en el prólogo: «La primera colectividad de la que me hice miembro fue, obviamente, la de mi barrio, la de mi esquina. Con ellos aprendí a sobrevivir -y a vacilarme- discurriendo por la brecha que divide lo legal de lo ilegal» (2000: 10).

Una de las tensiones entre los protagonistas y su entorno en la novela es la falta de empleo. El protagonista principal, $\mathrm{M}$, se une a una cola de postulantes en las céntricas calles Camaná y Moquegua, a la espera de ser entrevistado para un puesto de trabajo, que al final nunca obtiene. Desfilan desempleados, cambistas y mineros que protestan. Observamos entonces la amenaza de un enfrentamiento con los trabajadores de las minas llegados desde muy lejos a la capital para plantear sus reivindicaciones. "Cuando pasaron cerca, la gente se puso mosca, pues se sabía que en cualquier momento podían reventar los líos: la policía -en dos tanquetas y un microbús- los seguía de cerca» (2000: 40) El desempleo también alcanza a personajes que no son jóvenes. El episodio titulado Horas muertas nos muestra a José, el viejo camarero en el bar de Bigote, de quien había sido socio en tiempos anteriores y mejores:

Se decía que en un negocio anterior habían sido socios, hasta que un día se arruinaron. Bigote tenía ahorros y al poco tiempo pudo poner la cantinita. José, en cambio, se quedó sin un cobre y como hasta su mujer lo abandonó, terminó yendo a pedirle trabajo a su ex socio. (2000: 86)

El barrio, la esquina como punto de reunión, actúan como el escenario subterráneo para refugiarse del aburrimiento de una vida repetitiva y sin horizontes. Les brinda a los protagonistas una fuente de identidad y una tabla de salvación. Es el lugar donde se puede aparentar resistencia a pesar de estar vencidos: «La esquina, a veces transitado cruce de 
rutas microbuseras, con su perspectiva simultánea de cuatro calles que se extendían hacia lugares infinitos, era el sitio ideal para parapetarse de las propias desgracias personales sin que pareciera que lo estaban haciendo» (2000:29).

El desencanto y el escepticismo de los años 80 , como resultado de la decepción que provocaron los gobiernos democráticos posteriores a la dictadura militar de la década anterior, continúa en los años 90 y se refleja en particular en la literatura hecha por jóvenes narradores que publican sus primeras obras. Al final de la calle es una de esas obras que "encierra una mirada abierta y certera a una ciudad en crisis como Lima» (Vega 2004: 4). Los jóvenes protagonistas de la novela están tratando de reinventar valores para justificar su existencia. «Son los hijos de quienes no pudieron mudarse cuando el distrito comenzó a perder vigencia» (2000: 63) en la década de los años cuarenta.

\section{Literatura light, pero con resistencia pesada}

El surgimiento de Al final de la calle y de otras obras escritas por jóvenes narradores con temática similar, hizo que parte de la crítica las clasificaran como literatura light, comparándolas con las novelas y cuentos que aparecerían escritas por jóvenes narradores en otros países latinoamericanos. La crítica ha señalado que «el tema de la literatura light no es una categoría establecida por modelo de análisis textual alguno: no obstante su validez y pertinencia sigue discutiéndose y es blandida cuando conviene» (Sumalavia 2002: 5). Por otro lado, la denominación de literatura light en relación con una novela se ha convertido en 'acusación' de ser tan solo obra de entretenimiento con personajes inocuos que soportan pasivamente su realidad y que no cuestionan, resisten ni se rebelan ante la sociedad que les toca vivir. No obstante, antes que considerar a la novela Al final de la calle una obra solo de entretenimiento, se observa que a través de la música pop, el fútbol y el desenfreno personal, los personajes reaccionan ante su tiempo y espacio en que se encuentran. Se trata entonces de una novela que «utiliza los códigos de la cultura de masas para cuestionar el sistema social representado por la ciudad hegemónica, utilizando un discurso prosaico e irreverente, así como una temática donde el marginal, el joven sin espacio de desarrollo reclama y trastoca lo que será la nueva moral» (Sumalavia 2002: 5).

En la novela se puede hallar un cuestionamiento al sistema político con el voto viciado de $\mathrm{M}$ en las elecciones, mientras que su condición de omiso al servicio militar puede interpretarse como una crítica al militarismo que ha dominado buena parte de la historia 
republicana del país. El presentar un hospital como el lugar donde se vende sangre y órganos vitales para transplante al mejor precio, la destrucción de una cabina telefónica y el quemar un mapa del Perú es una forma literaria de querer destruir un sistema que solo les ofrece fracasos. En buena medida la cabina telefónica es una representación emblemática de la modernidad proclamada por el gobierno de la época ${ }^{2}$ y la destrucción del mapa es un gesto de transgresión, de deseo de liquidación del paisaje urbano que los rodea, sobre el cual se deberá construir otro más abarcador, más equitativo. Al final de la calle es una novela que carece de estructura en el sentido tradicional -o que quizás tiene una estructura compleja - que rompe la línea temporal y espacial. Es una historia escrita desde un nuevo realismo, que «trata de establecer, cuestionar y minar el nuevo espacio habitado por una juventud sin mayor norte que entregarse a las vicisitudes del momento» (Sumalavia 2002: 5).

\section{La amenaza del terror}

La novela también presenta la violencia del terrorismo que marcó a Lima en los años 80 y comienzos de los 90, y que paulatinamente se convirtió en uno de los marcadores del paisaje urbano de la capital. Continuamente nos encontramos con referencias a la siempre latente posibilidad de un atentado terrorista, o a la acción policial que detiene a jóvenes en su intento de ubicar y capturar a miembros de Sendero Luminoso. Por ejemplo, mientras hablan sobre las redadas policiales, como no tiene sus documentos de identidad en regla, Coyote le advierte a $\mathrm{M}$ de la posibilidad de ser enviados a lugares remotos del país para integrar la lucha antisubversiva: «Si te agarran, te mandan a Ayacucho o Huallaga, a pelear con los terrucos» (2000: 27). Más adelante, en el episodio titulado Luz negra, M y sus amigos se salvan por poco de ser afectados por la explosión de un coche-bomba, pero la buena suerte no los salva de observar los horrores del ataque: «-Se han volado a una vendedora de papa rellena y a su hijita. Estuvimos ayudando a sacar a la tía de debajo de un pedazo de carrocería. Dicen que de la nińa solo han encontrado un brazo y un trozo de cráneo. -contó Pacho» (2000: 110).

En el episodio titulado El estadio y la revolución, los protagonistas ven a un vendedor de El Diario, periódico vinculado a Sendero Luminoso, ofrecer su periódico tratando de

2 Dentro del programa de privatización de los servicios públicos llevados a cabo en la década de los 90 por el gobierno de Alberto Fujimori, la de la telefonía fue una de las que conllevó la más alta tasa de inversión por parte de una empresa extranjera. Los nuevos teléfonos públicos se convirtieron en símbolo de una aparente modernidad del país. 
propagar al mismo tiempo el mensaje político de la organización subversiva. El hecho de que esto ocurra en las tribunas del Estadio Nacional, a la vista y paciencia de la policía, nos recuerda los avances que había logrado la organización senderista en cuanto a presencia en la vida cotidiana de la sociedad peruana, y cómo se había convertido en elemento integrante del paisaje urbano de la ciudad capital.

Aunque la novela de Oscar Malca puede tener deficiencias formales, como ha señalado parte de la crítica, su carácter innovador, su representación del sector juvenil de la población peruana a fines del siglo XX, su diálogo con los medios de comunicación masiva y otros elementos de la cultura popular, la sitúan como la más representativa de la narrativa juvenil urbano marginal, siguiendo la tradición de narrativa urbana iniciada en la década de los años cincuenta en el Perú. Al final de la calle da cuenta de manera fragmentada de una ciudad violenta e indiferente, que tienen frente a sí un grupo de jóvenes que se desplazan por ella con su desesperanza y desilusión, a la que tratan de acomodarse para sobrevivir, ante una realidad particularmente dura, como lo fue el Perú de fines de los 80 y comienzos de los 90, en que se sitúa la novela. Exhibe un fructífero diálogo con los medios de comunicación masiva, los referentes culturales, la música rock subterránea, el fútbol, el frenético mundo de las drogas y el alcohol, la representación de la violencia terrorista de Sendero Luminoso y en general de la violencia de la sociedad limeña de fin de siglo. Siguiendo la línea trazada por la novela urbana de generaciones anteriores, y en especial la de Oswaldo Reynoso con su obra Los inocentes, Oscar Malca entrega un relato en el que M y los demás jóvenes protagonistas transitan marginalmente por las calles de su barrio y por su ciudad, reclamando un espacio propio, que la sociedad se empeña en negarles.

\section{Conclusión}

Los textos comentados nos ofrecen una lectura de los espacios vitales de la emergente clase popular, en Final del Porvenir, o de la pauperizada pequeña burguesía en Al final de la calle. Cada texto comentado incursiona en un espacio específico en el que se cuestiona y resiste la violencia y la marginalidad: ya sean el edificio multifamiliar, las calles de un barrio popular y un centro de abastos y sus inmediaciones, como escenario de la resistencia y la dimensión creativa de criollos, inmigrantes provincianos, afroperuanos y mestizos, todos unidos por la pobreza, para sobrellevar la difícil vida cotidiana de las clases populares, o las calles de un barrio de clase media venido a menos en el que los personajes abordan la ilegalidad, el deporte y la música popular para resistir y combatir su marginalidad. Se ha observado precisamente 
que en las obras analizadas los personajes se hallan en una construcción permanente de un espacio, principalmente de resistencia o contestación, desde el cual cuestionan, retan y tratan de superar los límites, convenciones y barreras sociales que les plantea el paisaje urbano en el que les toca vivir.

Final del Porvenir es una novela en la que se hace una lectura de Lima, que trae a primer plano los sentimientos y la experiencia de la exclusión, la inaccesibilidad y el desplazamiento de las tradicionales clases urbanas pobres. La constante inclusión de los nombres de las calles aledañas a la ubicación del conjunto habitacional recuerda al lector cómo se entremezcla y se atraviesa constantemente de lo real a lo imaginado. Es desde este espacio imaginado, que se parece tanto al real, que los personajes despliegan su resistencia al poder, encarnado principalmente por el Banco Popular, dueño del edificio, que pretende desalojarlos de sus viviendas en alquiler. En el proceso de lucha contra el desalojo, la novela revela a las instituciones públicas como entidades al servicio de los poderosos, a los mecanismos legales como instrumentos fuera del alcance y manejo de los pobres, a las fuerzas represivas como defensoras de los intereses de los poderosos, cuando los recursos formales y legales no consiguen su objetivo. El traslado de los pobladores a Comas al final de la novela parece una derrota de los habitantes del edificio El Porvenir, pero en efecto, es el comienzo de un 'nuevo porvenir', de un largo camino hacia la reconquista de la ciudad desde sus afueras, desde los márgenes, desde su perímetro. Comas, su destino después del desalojo, es entonces una pampa desierta en una zona de la ciudad que en un futuro habría de convertirse en uno de los componentes de lo que hoy son los tres 'conos' de Lima, el dinámico -en lo social, económico, arquitectónico y cultural- cinturón que rodea a la capital peruana, que aloja prácticamente el $60 \%$ de la población capitalina (Matos Mar 2006: 153). Los nombres de las viejas calles son dejados atrás y su victoria llegará con la apertura de nuevas calles, con otros nombres, con viviendas propias, con nuevos héroes y fechas que habrán de formar la nomenclatura identificadora de su nueva ciudad. La derrota de los pobladores de El Porvenir resulta ser solo temporal, la novela no muestra su fracaso sino la imposibilidad de acceso de los pobres a la ciudad oficial. Se cumple la sentencia de Wirth-Nesher que sugiere que las ciudades nos prometen plenitud, pero las hallamos inaccesibles (Wirth-Nesher 1996:7).

En Al final de la calle observamos que el personaje -en interacción con su paisaje urbano: la arquitectura, el entorno humano, los anuncios de cine, el tránsito vehicular, las colas en las oficinas que ofrecen empleo, las reuniones y fiestas con música juvenil, en 
particular el rock- resiste la vida rutinaria, la falta de perspectivas laborales, el vacío del entorno familiar, la difícil situación económica. Soporta y resiste estas condiciones mientras observa el deterioro que ha sufrido el barrio donde vive, que es el deterioro de la clase media en general.

Hay una resistencia callada, en la que $M$ es uno de los numerosos habitantes que se sienten impotentes ante su medio, frustrados frente al desorden imperante en la ciudad, la informalidad del comercio callejero, la delincuencia común, el fracaso estudiantil, la falta de trabajo remunerado con equidad. La aparente inercia de la gente se explica más por lo que esconde que por lo que revela el paisaje urbano que contemplan, en el que se desenvuelven. Los ambulantes, las prostitutas, los vendedores ambulantes, los mendigos y otros personajes están donde están, invadiendo las veredas, las calzadas, las plazas, las entradas a los cines y otros establecimientos públicos o de entretenimiento, porque la ciudad oficial los margina y no atiende sus necesidades, sus reclamos, sus derechos; la corrupción es generalizada, la ineficiencia caracteriza a sus servidores públicos, el sistema solo da oportunidad a una minoría. Por ello, M llegará al final de su calle y dejará de intentar obtener empleo por los mecanismos formales y seguirá el camino de la ilegalidad para traspasar las barreras de dicho marco social, para dejarlo atrás, para quizás, de ese modo, lograr su ascenso social.

Aunque ambas obras muestran la derrota de los personajes frente a la violencia de la exclusión social que los envuelve, no todo está perdido, pues en sus circunstancias, ante la falsedad de una modernidad y progreso pregonados desde las instancias oficiales, el fracaso es también una forma de resistencia. 


\section{REFERENCIAS}

Bances, Miguel

2003 «Iván Thays: El viaje interior». <http://moreferarum.perucultural.org.pe/ textos/moreferarum4/IvanThays.doc>. Consulta hecha en 12/05/2003.

Degregori, Luis Felipe

2006 Ciudad de M. Lima: Torre de Babel Producciones.

HigA, Augusto

1992 Final del Porvenir. Lima: Editorial Milla Batres.

Higgins, James

2004

Lima, A Cultural and Literary History. Oxford: Signal Books.

JARA JimÉnEZ, Cronwell

1998 «Visión de la violencia y del paisaje urbano de Lima en dos nuevas novelas». En Kohut, Karl, Morales Saravia, José y Sonia V. Rose (eds.). Literatura peruana hoy. Crisis y creación. Frankfurt y Madrid: Vervuert.

LEBLANC, Lauraine

1999

Pretty in Punk: Girls' Gender Resistance in a Boys'Subculture. New Brunswick, NJ, London.

López Degregori, Carlos y Jorge Eslava

2001 «La ciudad secuestrada; Cuatro autores de la narrativa peruana de los noventa». Lienzo, N. 22, Universidad de Lima.

Malca, Oscar

2000 [1995] Al final de la calle. 5. a ed. Lima: Libros de desvío.

MÁrquez, Ismael

1994

La retórica de la violencia en tres novelas peruana. New York: Peter Lang. 
Matos Mar, José

2000

Desborde popular y crisis del Estado veinte años después. Lima: Fondo Editorial del Congreso del Perú.

PANFichi, Aldo

2000

"Africanía, barrios populares y cultura criolla a principios del siglo XX". En Lo africano en la cultura criolla. Lima: Fondo editorial del Congreso del Perú.

2004

«Urbanización temprana de Lima: 1535-1900». En Panfichi, Aldo y Felipe Portocarrero (eds.). Mundos interiores: Lima 1850-1950. Lima: Universidad del Pacífico.

Sumalavia Chávez, Ricardo

2002

«Deslindes y cauces de la novísima narrativa peruana». Suplemento Identidades, diario El Peruano [Internet] <http://www.elperuano.com.pe/ identidades/09/id09.html>. Consulta hecha en 13/05/02.

Vega, Selenco

2004

«¿Cuál narrativa de los noventa?» <http://www.desco.org.pe/publicaciones/ QH/QH/qh122sv.htm>. Consulta hecha en 18/05/2004.

Velázquez Castro, Marcel

2004

«Nuevos sujetos y escenarios de la novela en los 90». <http://ajosyzafiros. perucultural.org.pe/02ensayo2h.htm>. Consulta hecha en 28/06/2004.

Wirth-Nesher, Hana

1996

City Codes. Reading the Modern Urban Novel. Cambridge: Cambridge University Press.

Wood, David 2005

"Reading the Game: The Role of Football in Peruvian Literature». The International Journal of the History of Sport, vol. 22, N. 2. 